\title{
(DES)ESPERANÇAS EM TEMPOS DE PANDEMIA: PROBLEMATIZAÇÕES SOBRE A COVID-19 A PARTIR DA GEOGRAFIA CRÍTICA
}

\author{
HOPE(LESSNESS) IN PANDEMIC TIMES: PROBLEMATIZATIONS ABOUT COVID-19 FROM \\ CRITICAL GEOGRAPHY
}

\author{
Lidiane Aparecida Alves \\ Doutora em Geografia pela Universidade Federal de Uberlândia \\ lidianeaa@yahoo.com
}

\begin{abstract}
RESUMO
A pandemia da COVID-19, em curso, consiste em um fenômeno geográfico intrinsicamente associado à globalização neoliberal, que tem causado vários questionamentos e incertezas. Logo, por sua essência, ela deve ser pensada a partir do espaço, sendo, portanto a Geografia chamada a oferecer contribuições para o seu entendimento. Nesse sentido, o presente artigo tem como objetivo realizar uma revisão crítica que permita o entendimento da expansão da COVID-19 em uma perspectiva geográfica. Deste modo, aborda-se os elementos que motivam as crises do período atual; a difusão e as consequências diferenciais da COVID-19 nos lugares de acordo com os usos do território, o que implica em exposição e vulnerabilidade distintas; e por fim, reflete-se sobre lições para o futuro considerando as possibilidades técnicas e ações disponíveis, ressaltando na perspectiva da saúde, a importância de seu entendimento a partir da determinação social e de sua promoção via Políticas Públicas intersetoriais. De fato é inegável que a conjuntura atual, de urgência e calamidades, evidencia muitas contradições/erros e consiste uma oportunidade para mudanças.
\end{abstract}

Palavras chave: Pandemia da COVID-19. Espaço geográfico. Desafios atuais e futuros.

\begin{abstract}
The COVID-19 pandemic consists of a geographic phenomenon intrinsically associated with neoliberal globalization, which has caused several questions and uncertainties. Therefore, due to its essence, it must be thought from space, therefore Geography is called to offer contributions to its understanding. In this sense, the present article aims to carry out a critical review that allows the understanding of the expansion of COVID-19 in a geographical perspective. In this way, it addresses the elements that motivate the crises of the current period; the diffusion and differential consequences of COVID-19 in places according to the uses of the territory, which implies different exposure and vulnerability; and finally, it reflects on lessons for the future considering the technical possibilities and available actions, emphasizing from the perspective of health, the importance of its understanding based on social determination and its promotion through intersectoral Public Policies. In fact, it is undeniable that the current situation, of urgency and calamities, shows many contradictions / errors and provides an opportunity for changes.
\end{abstract}

Keywords: COVID-19 pandemic. Geographic space. Current and future challenges.

\section{INTRODUÇÃO}

A pandemia da COVID-19 provocada pelo novo coronavírus é um fenômeno eminentemente geográfico, que pode ser analisada pela Geografia a partir de vários enfoques, conforme constata-se pelas publicações e reflexões realizadas por geógrafos de todo o mundo e de distintas cadeiras. No entanto, ao considerar a dimensão da complexidade e das incertezas inerentes ao momento atual

Recebido em: 28/04/2020

Aceito para publicação em: 02/06/2020. 
torna-se pertinente uma perspectiva dialógica, quer do ponto de vista conceitual, quer no que se refere ao conhecimento da realidade. Nesse sentido, as teorizações de intelectuais como o geógrafo brasileiro Milton Santos, que dialoga com outros autores, como o filósofo e sociólogo Edgar Morin e o sociólogo Boaventura de Sousa Santos, consistem em um dos encaminhamentos para fundamentar as reflexões sobre a situação da pandemia.

Assim sendo, toma-se como ponto de partida para tecer considerações sobre a conjuntura atual, o espaço geográfico, o qual resulta da interação permanente entre homem e natureza, por meio de técnicas e políticas inerentes ao processo de produção, portanto entendido como território usado. Ademais, deve-se considerar a totalidade da práxis cotidiana, na qual são evidenciadas a materialização da racionalidade técnica, as necessidades, as solidariedades e os conflitos vivenciados pelos cidadãos comuns, que permitem compreender as particularidades de cada lugar, e pensar nas possibilidades de transição para novos sentidos para existência da sociedade no planeta. Neste sentido, destaca-se o papel do lugar, enquanto o espaço banal, irredutível e vivido, que apresenta-se como "objeto de uma razão global e de uma razão local, convivendo dialeticamente" (SANTOS, 1997, p.273).

Logo, a partir do espaço geográfico considerando, especificamente o território e o lugar pode-se geografizar e historicizar a totalidade-mundo, reconhecer as desigualdades engendradas pela globalização, mais evidentes com a pandemia, distinguir e valorizar as resistências, as situações de mal-estar e de escassez, enfim considerar "uma pedagogia da existência" (SANTOS, 2000) que possa levar à guinada para novas consciências e para um novo modelo político-econômico mais solidários, ressignificando o tempo-espaço.

Nesse sentido, o presente artigo tem como objetivo realizar uma revisão de literatura que permita o entendimento da expansão da COVID-19 em uma perspectiva geográfica. Portanto, o texto trata de uma revisão da literatura no qual aborda-se os elementos que motivam as crises do período atual; a difusão e as consequências diferenciais da COVID-19 nos lugares de acordo com os usos do território, que implicam em diferentes graus de exposição e vulnerabilidade já que a saúde é determinada socialmente; e por fim, reflete-se sobre lições para o futuro considerando as possibilidades técnicas e ações disponíveis, ressaltando na perspectiva da saúde, a importância de seu entendimento a partir da determinação social e de sua promoção via Políticas Públicas intersetoriais que tenham como base o lugar.

\section{OS DESAFIOS ATUAIS E SUAS RAÍZES}

O período atual, especificamente o século $X X I$, caracteriza-se como um período e uma crise de alcance planetário conforme apontado por Santos (2000). Como período o autor destaca a ocorrência da globalização explicada pela unicidade da técnica e do tempo, pela mais valia globalizada e cognoscibilidade do planeta. Como crise aponta que essa é estrutural e ocorre de maneira sucessiva, devido à persistência da necessidade de novos arranjos das variáveis que constituem o sistema. Conforme apontam Santos (2000) e Santos (2020) a crise transforma-se na causa que explica todos os demais problemas, sendo que não se busca soluções para ela. De modo geral, as medidas adotadas, legitimadas pelo sistema ideológico, pelo "pensamento único", que tem como base a tirania o dinheiro e da informação, não são estruturais, mas servem para atender aos interesses dos atores hegemônicos. Consequentemente, tais medidas geram e/ou aprofundam outras crises como a econômica, social, política, moral, ecológica etc. sendo a manutenção das desigualdades socioespaciais é necessária.

Neste "período que é uma crise" Santos (2000), ou ainda, um "permanente estado de crises", Santos (2020) ao tecer considerações sobre a "trágica transparência do coronavírus", lança luz a três elementos invisíveis todo-poderosos, que são as raízes das crises. Eles são os eficazes, ferozes e destemperados modos de dominação: do capitalismo, do colonialismo e do patriarcado. Logo,

Apesar de serem omnipresentes na vida dos humanos e das sociedades, são invisíveis na sua essência e na essencial articulação entre eles. A invisibilidade decorre de um sentido comum inculcado nos seres humanos pela educação e pela doutrinação permanentes. Esse sentido comum é evidente e é contraditório ao mesmo tempo. Todos os seres humanos são iguais (afirma o capitalismo); mas, como há diferenças naturais entre eles, a igualdade entre os inferiores não pode coincidir com a igualdade entre os superiores (afirmam o colonialismo e o patriarcado). (SANTOS, 2020, p.12). 
Segundo Santos (2020) desde o século XVII, tais modos de dominação persistem seja de maneira aparentemente inabalável, como o caso do capitalismo, seja de modo dissimulado e metamorfoseado em neocolonialismo, dependência, como no colonialismo ou de modo velado como o patriarcado, que aparece na violência doméstica, na discriminação sexista e no feminicídio. O autor destaca ainda que a pandemia tem evidenciado as consequências destes três modos de dominação, que são: "a escandalosa concentração de riqueza/extrema desigualdade social e a destruição da vida do planeta/iminente catástrofe ecológica" (SANTOS, 2020, p.13).

Ao considerar a evolução da relação do homem com a natureza, que é portadora e produtoras de técnicas, e o desenvolvimento das ideias filosóficas, Santos (2000) e Morin et al (2007) concordam que ocorreram avanços na ciência e nas técnicas sem, no entanto avanços éticos, haja vista a prevalência do culto ao mercado em detrimento das necessidades básicas. Santos (2000) ressalta que até fim da Segunda Guerra Mundial existiram avanços na cidadania, ainda que essa nunca tenha sido plenamente alcançada. Todavia, a globalização rompeu com as evoluções, porque materializouse a serviço do mercado e do dinheiro em estado puro e não para a humanização da vida no planeta. Portanto, ao assim concretizar segundo o autor, "a globalização mata a noção de solidariedade, devolve o homem à condição primitiva do cada um por si e, como se voltássemos a ser animais da selva, reduz as noções de moralidade pública e particular a um quase nada" (SANTOS, 2000, p. 65).

Nesse contexto, o capitalismo globalizado e tudo o que ele envolve, como o neoliberalismo, leva à intensificação da exploração sem limites dos recursos naturais, às adaptações do território para atender as necessidades do capital, subordinando o poder público e reduzindo os recursos do Estado para o social, cujas ações produzem desequilíbrios, fragmentações e desordens. Prontamente, dentre outras consequências como o aumento da pobreza estrutural, majora-se a probabilidade de perturbações ecossistêmicas e de emergência de doenças, que tem relação com "a morte desnecessária de muitos seres vivos da Mãe Terra, nossa casa comum" (SANTOS, 2020, p.23) e com a "iminência de a Terra não suportar nossa demanda" (KRENAK, 2020, p.25).

Nesse sentido, compartilha-se com a visão de Santos (2020) e de Krenak (2020) de que as pandemias, não são vinganças da natureza, mas são manifestações da auto-defesa do planeta para garantir a sua biodiversidade. Uma "obra de uma mãe amorosa que decidiu fazer seu filho calar a boca" (KRENAK, 2020, p.54) para Ihe ensinar, que existe uma pluralidade de formas de vida, "a vida humana é uma ínfima parte $(0,01 \%)$ da vida planetária" (SANTOS, 2020, p.23), cuja sobrevivência depende do reconhecimento de que a humanidade é parte da natureza.

Morin et al (2007) já alertaram que a vida é uma consequência da história da Terra, que é uma entidade planetária e biosférica, a qual consiste na casa de todos. Entretanto, desde o século XV tendo como base a cultura ocidental e sua busca cega pelo progresso (cuja palavra chave é o desenvolvimento, que na verdade pode ser reduzido a crescimento econômico ou consumo) tudo vem sendo sacrificado para alcançá-lo. Portanto, os autores alertam que o quadrimotor: ciência, técnica, indústria e interesse econômico tem gerado males como a degradação ambiental, cujas consequências são planetárias. Logo há que se concordar que,

\begin{abstract}
[...] la emergencia de estas pandemias de la globalización no tiene nada de 'desastre natural' o de un 'hecho fortuito que tarde o temprano tenía que pasar'. Más bien son el resultado del avance neoliberal de mercantilización de la vida y ocupación de nuevas fronteras ecosistémicas de las últimas décadas: agricultura y avicultura intensivas e industriales (que propiciaron la gripe aviar), comercio de animales salvajes y exóticos (como ocurre en China), manipulación genética, expansión del turismo depredador, deforestación, abusos en el consumo de antibióticos, por mencionar ejemplos. Factores como estos se potenciaron con una forma transnacional de transmisión, posible por la expansión de las interconexiones de la movilidad humana y de mercancías, el extraordinario crecimiento de las ciudades, la precarización de los sistemas de salud pública, entre otros. (MANTOVANI, 2020, $\mathrm{s} / \mathrm{p})$.
\end{abstract}

Diante do exposto, concorda-se com Harvey (2020 s/p) e Zibechi (2020 s/p) no sentido de que a difusão do neoliberalismo, a partir dos anos 1970/1980, que causou danos ambientais, de saúde e sociais provavelmente irreparáveis, implicou em maiores impactos da pandemia do coronavírus na população mal preparada para enfrentar essa crise. Na perspectiva da saúde, com o neoliberalismo ela não é tratada como um direito fundamental, sendo que os sistemas de saúde passam a ser orientados pela lógica do mercado, não atendendo adequadamente a todos nas demandas cotidianas. Assim sendo, conforme alerta Morin (2020, s/p), 


\begin{abstract}
Atualmente nós estamos sujeitos a uma tripla crise. A crise biológica de uma epidemia que ameaça indiscriminadamente nossas vidas e ultrapassa as capacidades hospitalares, sobretudo onde as políticas neoliberais não cessam de reduzi-las. A crise econômica nascida das medidas de restrição tomadas contra a pandemia e que, reduzindo ou parando as atividades produtivas, de trabalho, de transporte, certamente se agravará se o confinamento se tornar duradouro. A crise de civilização: nós passamos bruscamente de uma civilização da mobilidade a uma obrigação de imobilidade [...] Essas crises são interdependentes e estabelecem relações umas com as outras. [...] Mais profundamente, esta crise é antropológica: ela nos revela a face ínfima e vulnerável da formidável força humana, ela nos revela que a unificação técnico-econômica do globo criou, ao mesmo tempo, uma interdependência generalizada e uma comunidade de destino sem solidariedade.
\end{abstract}

O alerta de Morin (2020), já declarado previamente pelo autor, Morin (2002) e Morin et al. (2007) e compartilhado por vários pensadores das ciências sociais de viés humanista como: Santos (2000), Santos (2020), Krenak (2020), Mantovani (2020) etc, reforça que eventos como a pandemia do coronavírus são uma consequências do aumento das complexidades e insustentabilidade inerente ao capitalismo neoliberal globalizado e a sua obsessão pela lucratividade. Além disso, ela também é mais um dos sintomas da crise da civilização moderna, reconhecida e intensificada desde os anos de 1970/1980. Portanto, ela põe em xeque os limites do capitalismo e da globalização, posto que mostra as desigualdades, a fragilidade da produção e circulação global em rede, além de gerar incertezas quanto ao futuro da forma da vida da humanidade na Terra.

\title{
EMERGÊNCIA E DIFUSÃO DO CORONAVÍRUS
}

Diante das vertiginosas transformações socioespaciais, nomeadamente ambientais $e$ socioeconômicas, que ocorrem no mundo alterando a forma de interação da sociedade com a natureza cientistas são consensuais em relação à potencialidade para a emergência de epidemias internacionais, causadas por patógenos (bactérias e vírus) de origem animal que passariam para humanos. Em 2018 a Organização Mundial da Saúde (OMS) ao publicar a revisão da lista de doenças e patógenos que deveriam ter atenção especial, por "representarem um risco para a saúde pública devido ao seu potencial epidêmico e para as quais não existem contramedidas ou medidas suficientes", a organização incluiu uma "doença X" para se referir a algo inesperado que poderia emergir de um patógeno desconhecido (WHO, 2018).

De fato, no final de 2019 emergiu na cidade de Wuhan, na Província de Hubei, na extremidade ocidental da região sudoeste da China uma doença causada por um novo coronavírus, SARS-CoV22, que foi divulgada publicamente pelo governo chinês no final de dezembro e passou a partir de fevereiro a ser científica e oficialmente designada pela Organização Mundial da Saúde (OMS) de COVID-193. COVID significa COrona VIrus Disease (Doença do Coronavírus), enquanto "19" se refere a 2019, ano de sua emergência (FIOCRUZ, 2020).

Logo, hodiernamente ao considerar a emergência e difusão da COVID-19, há apontamentos de epidemiologistas de que ela atende aos critérios e pode ser a "doença X" (NAVAS, 2020). Ademais, estudiosos concordam que essa não será a última pandemia a ser enfrentada nos próximos anos, outros patógenos podem sair de animais e passarem para a população humana. Haja vista a combinação de fatores como a expansão da população humana, associada à mudanças climáticas, globalização e intensificação da produção animal, conforme destacado por Zanella (2016).

Além disso, verifica-se que mesmo com os alertas não se dispensou(a) a devida importância, nomeadamente quanto ao financiamento das pesquisas científicas sobre as doenças emergentes, que são riscos crescentes e tem potencial para ocorrer em qualquer lugar do planeta, nomeadamente naqueles mais unidos verticalmente pela globalização.

Afinal, tomando como base Santos $(1997,2000)$ tem-se que "cada lugar é, à sua maneira, o mundo", sendo que com a difusão do capitalismo globalizado as ordens hegemônicas globais materializam-se localmente, de acordo com as virtualidades particulares de cada lugar, impondo a sua racionalidade, alterando o ambiente e unindo verticalmente os lugares, enquanto espaço de fluxos a serviço do mercado, vivenciados pelos homens rápidos. Esses são também designados de "espaços luminosos",

\footnotetext{
${ }^{2}$ Análises genômicas do vírus apontam que os morcegos foram a origem mais provável do coronavírus.

${ }^{3}$ A denominação é importante para evitar casos de xenofobia e preconceito, além de confusões com outras doenças. (FIOCRUZ, 2020).

DOI:http://dx.doi.org/10.14393/Hygeia0054269 $\quad$ Hygeia $\quad$ Edição Especial: Covid-19, Jun./2020 p.25 - 35, pág. 28
} 
posto que concentram altas densidades técnicas (aeroportos, portos, rodovias, etc.), redes e fluxos de transportes e recursos como é o caso de metrópoles globais como São Paulo e Nova York.

Cabe destacar que a despeito das (des)ordens impostas a partir de uma única racionalidade, em que o território é usado enquanto recurso, ao serem particulares, cada lugar responde a essa imposição à sua maneira, bem como resistem a partir das solidariedades horizontais (estabelecidas organicamente no espaço de todos, o espaço banal) e das contra-racionalidades (formas de convivência e regulação próprias de um território), que tem como base a proximidade e os homens lentos. Neste caso, a união dos lugares ocorre a partir do uso do território para além de mero recurso, mas que serve ao homem como abrigo, abarcando as dimensões econômica, social, cultural e geográfica. Por vezes, tais lugares consistem nos chamados espaços opacos, conforme designação utilizada por Santos (1997) para se referir aos espaços onde vivem os pobres, caracterizados pelas carências de todos os tipos de consumo (in)material, político, cidadania, enfim nos espaços onde vive a maioria da população, especialmente considerando realidades "moderno-periférico-coloniais" como a nossa. (SANTOS, 1997, 2000).

Portanto, considerando tanto as particularidades e "forças/resistências" do lugar, essa categoria assume especial importância para as reflexões sobre a difusão diferencial, os desdobramentos imediatos e futuros da pandemia da COVID-19, que conforme destacado por Castilho (2020) metaforicamente possui o DNA da globalização e, assim sendo tende a germinar a perversidade crua, impiedosa, insana nas periferias, bem como pode ser a possibilidade para um devir.

Na perspectiva da difusão dessa pandemia, a partir do mapeamento dos casos, como na iniciativa RADAR COVID-194 os estudiosos apontam que a difusão do vírus, considerando tanto a contiguidade física (em mancha de óleo) como as interações espaciais existentes na rede urbana brasileira, que acontece de forma hierárquica.

Os casos se difundem a partir do topo da pirâmide socioeconômica, entre as classes mais privilegiadas, que de modo geral estão nos "espaços luminosos", segundo a designação de Santos (1997) cujos espaços são marcados hiperconectividade e tendências como a Internet das Coisas, Indústria 4.0 etc. No Brasil, por exemplo, os primeiros casos de infectados pelo coronavírus foram notificados em São Paulo, um ponto luminoso e/ou hiperconectado, sendo que nesse momento a difusão da COVID-19 foi altamente permeável graças à associação da levada capacidade de contágio, período assintomático superior a outras doenças e relações verticais entre os locais.

Ao observar as escalas nacional e estaduais a irradiação do coronavírus ocorre de modo desigual, espacial e temporalmente, com o maior número de casos, primeiramente nos "espaços luminosos", considerando tanto o espaço interurbano (a rede urbana) como o espaço intraurbano, em uma segunda fase da pandemia difunde-se para os demais espaços geográficos, seja de modo contíguo ou a partir de polos por interação funcional, até chegar aos "espaços opacos".

Os fatos e processos estão em curso, entretanto o que já se conhece em relação ao comportamento do vírus e sua disseminação nas periferias pobres, adensadas e precárias é motivo de grandes preocupações. Afinal a difusão da pandemia atual nos espaços dos idosos (asilos, casas de repouso), espaços de reclusão e nos "espaços opacos" tem desdobramentos mais dramáticos, com mais vítimas fatais. Ao considerar os grupos que vivem nestes espaços, em zonas de invisibilidade, cuja vulnerabilidade precede a quarentena e se agrava com ela, Santos (2020) os designa de Sul, não na concepção de um espaço geográfico, mas de espaço-tempo político, social e cultural. Como "metáfora do sofrimento humano injusto causado pela exploração capitalista, pela discriminação racial e pela discriminação sexual” (SANTOS, 2020, p.15).

Nesse contexto, fica claro que o vírus não é democrático, porque afeta de modo mais brutal tais grupos já mais fragilizados e que não dispõem de condições para o isolamento social. Santos (2020) destaca que apesar de menos discriminatórias que outras violências, as pandemias como a atual não matam tão indiscriminadamente quanto se julga. Afinal, tanto em relação à sua prevenção, como à sua expansão e mitigação, há grupos como o das mulheres, dos trabalhadores precários, dos moradores de favelas, dos refugiados e populações deslocadas, deficientes, idosos, etc. (aqueles que estão a sul da quarentena, cuja lista está longe de ser exaustiva), com níveis suscetibilidade e de vulnerabilidade superiores, pois estão mais expostos à propagação do vírus e o atendimento à saúde

\footnotetext{
4 Trata-se de uma iniciativa de um grupo multidisciplinar de pesquisadores da Faculdade de Ciências e Tecnologia, Campus de Presidente Prudente da Universidade Estadual Paulista "Júlio de Mesquita Filho" (FCTUNESP), referente à disseminação do novo coronavírus (COVID-19).

DOI:http://dx.doi.org/10.14393/Hygeia0054269 Hygeia $\quad$ Edição Especial: Covid-19, Jun./2020 $\quad$ p.25 - 35, pág. 29
} 
não é aplicado de modo universal. Fatos que evidenciam potenciais causas para resultados diferenciados no grau de incidência de infectados e mortos pela da COVID-19.

As mulheres, vivenciam o aumento de stress, posto que muitas ocupam profissões como enfermagem, assistência social, cuidadoras etc. e sofrem com o aumento da violência doméstica, conforme apontam estatísticas de países de diversas partes do mundo e/ou também, nos primeiros meses de propagação da COVID-19 estão sendo as mais atingidas pelas infecções provocadas pelo coronavírus. Na cidade de São Paulo ou no Estado de Minas Gerais, por exemplo, considerando tanto os casos confirmados como suspeitos, as mulheres adultas (30 a 39 anos) são as mais infectadas. A figura 1, referente ao perfil demográfico dos infectados pelo coronavírus no período de 7 de fevereiro à 26 de abril, mostra a proporção maior de mulheres jovens infectadas em Minas Gerais. Deve-se, no entanto, destacar que as mulheres representam a maior parte da população brasileira, assim como têm o hábito de procurarem mais a atenção médica. Acrescenta-se também que, nomeadamente no caso brasileiro, ainda é preciso tempo para que sejam realizadas analises mais pormenorizadas a respeito do perfil demografico dos contaminados por COVID-19, afinal a difusão da COVID-19 ainda está em curso no país.

Figura 1 - Casos de COVID-19 em Minas Gerais por sexo e faixa etária (27 abr. 2020).

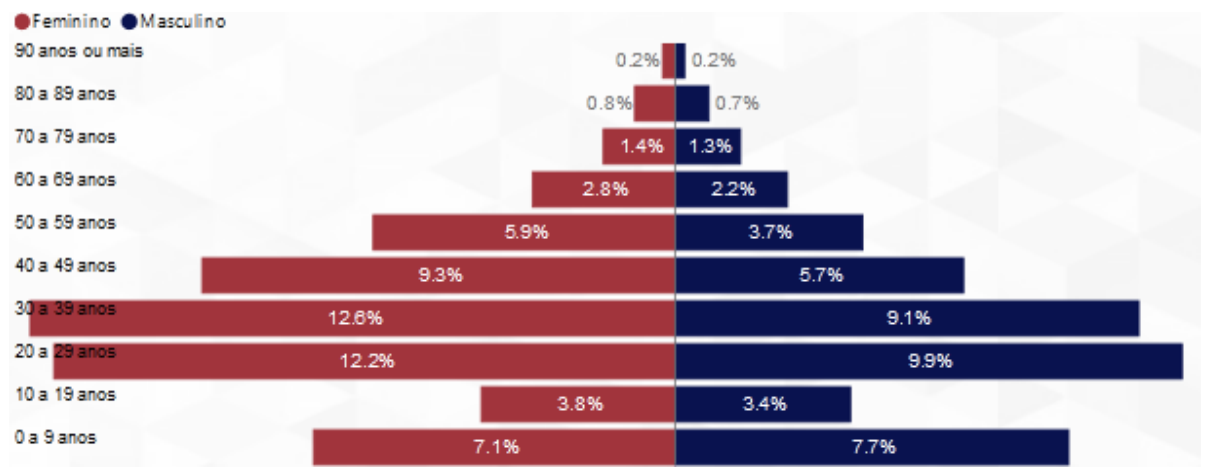

Fonte: https://www.saude.mg.gov.br/coronavirus. Acesso em: 27 abr.2020.

Outro grupo é formado pelos trabalhadores precários, informais, ditos autônomos e os trabalhadores da rua, geralmente ocupantes do setor de serviços que viram nos últimos anos, em decorrência das políticas neoliberais, constantes perdas dos direitos trabalhistas e/ou ganham dia-a-dia para viver dia-a-dia no setor informal, e agora encontram-se na encruzilhada entre o ariscar sobreviver ao vírus ou a fome (SANTOS, 2020). Tais trabalhadores geralmente são também moradores das periferias pobres das cidades, favelas que além da atual emergência sanitária vivem muitas outras decorrente de distintas epidemias relacionadas à falta de saneamento básico ${ }^{5}$, à coabitação e à precariedade das moradias, à falta de atenção médica, à falta de segurança alimentar, às constantes tipos de violência física e psicológica, entre outros fatores que podem potencializar a transmissão do vírus, assim como sua taxa de mortalidade, já que muitas pessoas podem ter comorbidades e ter quadro grave da COVID-19. Os dados referentes à cidade de São Paulo disponibilizados em 23 de abril de 2020 já revelam que as periferias das cidades concentram o maior número de mortes por coronavírus (VICENTE, 2020; SEADE, 2020).

Acrescenta-se ainda as pessoas em campos de refugiados, imigrantes sem documentos ou populações deslocadas internamente, que vivem sem mínimas condições de habitabilidade, distantes de unidades de saúde, sendo a propagação do coronavírus entre eles "fatais e ainda mais dramáticos do que os que enfrentam as populações das periferias pobres". (SANTOS, 2020).

\footnotetext{
${ }^{5}$ No Brasil, de acordo com o Sistema Nacional de Informação sobre Saneamento (SNIS) o atendimento de água chega a $83,6 \%$ da população, enquanto a rede de esgoto alcança $53,2 \%$.

DOI:http://dx.doi.org/10.14393/Hygeia0054269 $\quad$ Hygeia Edição Especial: Covid-19, Jun./2020 p.25 - 35, $\quad$ pág. 30
} 
Ao considerar os dobramentos da quarentena ${ }^{6}$ concorda-se que ela expõe assimetrias históricas, nas palavras de Santos (2020) "a quarentena não só torna mais visíveis, como reforça a injustiça, a discriminação, a exclusão social e o sofrimento imerecido que elas provocam". Assim como evidencia que as desigualdades implicam em exposição, suscetibilidade e vulnerabilidade e, portanto consequências mais dramáticas para os "grupos do sul". Nesse contexto, a premissa biopolítica de Foucault do direito de vida e de morte é aplicada.

Especialmente considerando o contexto brasileiro, para compreender as diferenças internas na difusão do COVID-19 nos centros urbanos destaca-se a relevância de se considerar que a saúde é socialmente determinada. Afinal, a despeito de se atribuir a estrutura etária, a fluidez/mobilidade e as comorbidades como fatores explicativos principais para a distribuição desigual dos casos de COVID19, conforme destaca Ferrão (2020) há evidencias de que áreas com população envelhecida não são necessariamente as mais suscetíveis, tal situação depende do grau de exposição e vulnerabilidade (maiores entre os mais pobres).

Nesse sentido, destaca-se a viabilidade de se considerar os determinantes da saúde. De acordo com Organização Mundial de Saúde (OMS) a saúde de um indivíduo é um conceito complexo, multidimensional e dinâmico, determinada pelas condições que as pessoas nascem, crescem, vivem, trabalham e envelhecem, as quais são moldadas pela distribuição de dinheiro poder e recursos a nível global, nacional e local, portanto pelas condições sociais, ambientais e econômicas. Em meados do século XIX, Rudolf Virchow já afirmava que as condições econômicas e sociais exercem um efeito importante sobre a saúde e a doença (BUSS; PELLEGRINI FILHO, 2007).

$\mathrm{Na}$ literatura foram propostos modelos para descrever a relação entre os diferentes fatores que influenciam a saúde. Um deles é o modelo de Dahlgren e Whitehead (1991) em que fatores determinantes da saúde são compreendidos a partir de diferentes níveis (figura 2).

Figura 2 - Principais determinantes da saúde para Dahlgren e Whitehead (1991).

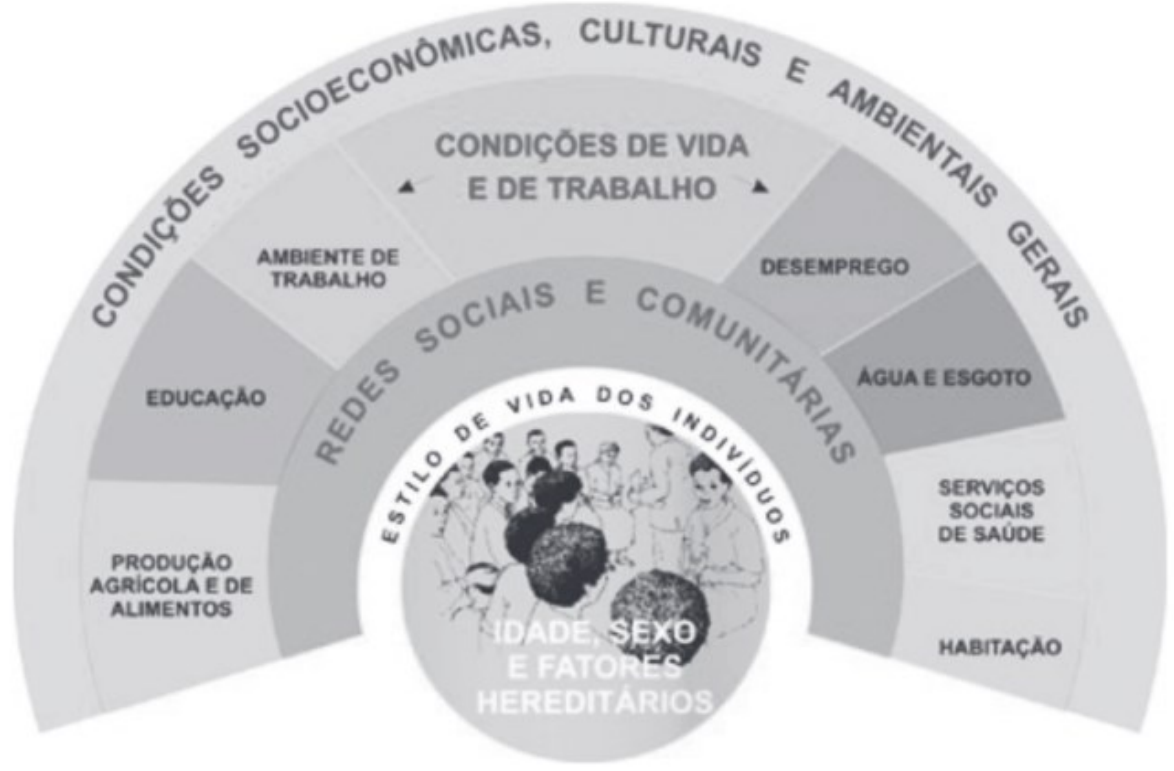

Fonte: Buss; Pellegrini Filho (2007).

6 Destaca-se que os termos quarentena, distanciamento social, isolamento social e confinamento social são distintos, apesar de serem aplicados com o mesmo objetivo: evitar novas infecções. Em síntese a quarentena refere-se à medida ancestral aplicada àqueles presumivelmente expostos a uma doença contagiosa, mas que não estão doentes. Ela ser para conter a difusão de uma epidemia. Já o distanciamento social trata-se de uma medida de prevenção primária, que visa à diminuição de interação entre as pessoas de uma comunidade para diminuir a velocidade de transmissão de um vírus. O isolamento social, por sua vez, serve para separar pessoas sintomáticas ou assintomáticas, que foram contaminadas ou estão com suspeita. Dependendo da situação, os pacientes podem ficar isolados em ambiente domiciliar ou em hospitais. E por fim, o lockdown ou confinamento social surge como medida compulsiva, com recursos à violência de Estado e aplicação de multas e detenções para quem desrespeitar a medida de não sair de casa, a não ser em casos excepcionais (UFGRS,2020).

DOI:http://dx.doi.org/10.14393/Hygeia0054269 Hygeia Edição Especial: Covid-19, Jun./2020 p.25 - 35, pág. 31 
No centro os autores destacam características individuais (sexo, idade, características hereditárias), já no nível mais distal são consideradas as condições socioeconômicas, culturais e ambientais, ou seja, os macro determinantes de saúde, e entre estes dois níveis aparecem as condições de vida e trabalho (emprego, saneamento, serviços de saúde, habitação, educação, alimentos, ambiente de trabalho, etc.), as influências sociais e da comunidade (redes de apoio, que se expressam em coesão social) e os estilos de vida individuais.

As relações dos determinantes e a saúde não são simples e diretas, de causa-efeito, mas complexas. Entretanto, os determinantes da saúde que contribuem para explicar as diferenças entre as expectativas de vida entre os mais ricos e os mais pobres a partir das circunstâncias socioambientais, também podem permitir identificar questões relevantes em relação à distribuição dos casos de COVID-19 nomeadamente na escala municipal. Afinal, sabe-se que as condições em que uma pessoa mora ou vive, afeta suas condições de saúde, de modo que ela então poderá, eventualmente, ser mais severamente afetada pela COVID-19.

\section{PEDAGOGIAS DO CORONAVÍRUS: ALGUMAS PERSPECTIVAS FUTURAS}

Tendo como fundamento os ensinamentos de Santos (2000) de que na evolução da humanidade os períodos nascem, amadurecem e morrem, e de Gramsci (1929, p. 276.), ainda que ele se referisse a outros tempos, a ideia de que "a crise consiste precisamente no fato de que o velho está morrendo e o novo ainda não pode nascer. Nesse interregno, uma grande variedade de sintomas mórbidos aparecem" também aplica-se ao período e a crise atual. Sinais de transição revolucionária podem ser identificados ao considerar o período imediatamente anterior à pandemia, quando em vários pontos do planeta já era notável a ocorrência de contratendências, movimentos e protestos contra as desigualdades sociais, a falta de proteção social, a destruição da natureza etc. os quais tendem a aumentar após o período de quarentena, posto que a pobreza e a extrema pobreza certamente aumentarão.

Nesse contexto, não é fato isolado, mas é compartilhada por vários autores, a perspectiva de que a situação atual traz várias questões incômodas e apresenta-se como uma lição para o futuro, uma possibilidade para refletir sobre o paradigma de produção vigente, sobre o sentido da humanidade e da vida, da relação da sociedade com a natureza, dos ritmos e tempos que devemos valorizar, sobre a importância do Estado, do planejamento e de uma comunidade solidária, sobre os limites do antropocentrismo, entre outras questões relacionadas com a necessidade de uma "regeneração ética da sociedade e do mundo" (MORIN et al, 2007), que considere a interdisciplinaridade, a complexidade, as incertezas e as diversidades da/na Terra. Nesse caso, trata-se de uma possibilidade para imaginação e a criatividade humana mudar positivamente o mundo. Entretanto, conforme alertado por intelectuais de vanguarda como Noam Chomsky e Giorgio Agamben há que se considerar os riscos da emergência de Estados de exceção, colocando em causa a própria democracia. Nesse sentido, ainda que neste texto não se tenha o objetivo de abordar as questões intrínsecas à biopolítica e a necropolítica ressalta-se a importância de se ampliar o entendimento a cerca de tais temas extremamente atuais.

Tendo como base aspectos estruturais da humanidade merece atenção especial as reflexões que instigam para emergência de um novo modelo civilizatório, um novo sistema político-ecológico-econômicosocial, que tenha como base soluções centradas no homem enquanto "cidadãos da Terra" (MORIN, et al.2007) e que vislumbrem a possiblidade de uma outra economia, em que o "interesse social preceda o interesse econômico" (SANTOS, 2000), conforme já defendido por vários estudiosos críticos do capitalismo.

Na perspectiva da reflexão sobre o sentido da vida e o que se entende por humanidade, tendo em vista a possibilidade de uma regeneração humanística compartilha-se com o ponto de vista de Morin (2020) no sentido de que

O humanismo tomou duas faces antagônicas na Europa. A primeira é aquela da quasedivinização do humano, destinado a dominar a natureza. O outro humanismo foi formulado por Montaigne em uma frase: "eu reconheço em todo homem meu compatriota". É necessário abandonar o primeiro e regenerar o segundo. A definição do humano não pode se limitar à ideia de indivíduo. O humano se define por três termos tão inseparáveis um do outro quanto a trindade: o humano é ao mesmo tempo indivíduo, uma parte, um momento da espécie humana, e uma parte, um momento da sociedade. Ele é simultaneamente individual, biológico, social. A partir desse momento, o humanismo não saberia ignorar nossa ligação umbilical com a vida e nossa ligação umbilical com o universo. Ele não se esqueceria que a natureza está tanto em nós como nós estamos na natureza. A base intelectual do humanismo regenerado é a razão 
sensível e complexa. Não somente é necessário seguir o axioma "não há razão sem paixão, não há paixão sem razão", mas nossa razão deve sempre ser sensível a tudo que afeta os humanos. (MORIN, 2020, s/p).

Em relação à racionalidade político-econômica, o momento é oportuno para mudanças porque "El sistema capitalista se estremece en su propia constitución. Nunca en su historia el capitalismo había tenido tantas grietas" (MANTOVANI, 2020). Desse modo ao mostrar como o mercado e o neoliberalismo alienaram lugares e incapacitou o Estado para atender as demandas sociais e para responder as emergências como a provocada pela COVID-19 "a ideia conservadora de que não há alternativa ao modo de vida imposto pelo hipercapitalismo em que vivemos cai por terra. Mostra-se que só não há alternativas porque o sistema político democrático foi levado a deixar de discutir as alternativas" (SANTOS, 2020, p.6). Sendo assim, não restam dúvidas sobre "a importância do regresso do Estado e da comunidade" (SANTOS, 2020).

Ao considerar a saúde uma mudança relevante seria a implementação de Políticas Públicas voltadas para a sua promoção. Nesse sentido, ressalta-se a importância de que sejam consideradas ações específicas no setor de saúde como aquelas voltadas para prevenção de doenças e valorização dos profissionais, mas também em outros setores como na educação, tanto na básica buscando a formação de cidadãos conscientes e comprometidos com a "construção de uma civilização planetária" (MORIN, 2007) como no ensino superior valorizando as pesquisas científicas, fundamentais a conquista do bem-estar social, entendido como condição para cidadania e para a qualidade de vida, não podendo ser consumo ou acúmulo de bens.

Isso representaria a consideração, para além dos aplausos das sacadas, ao pessoal da saúde. E o mais importante, o reconhecimento da importância de considerar a saúde não como meramente a ausência de doença, mas como o bem-estar físico, psíquico e social completo, conforme preconizado pela Organização Mundial de Saúde (OMS). Além da valorização de um serviço nacional universal de saúde como o Sistema Único de Saúde (SUS) que assegure a todos os cuidados, de baixa a alta complexidade, sem qualquer custo.

A maneira que tais questões forem interpretadas e avaliadas, nas palavras de Santos $(2020$, p.10) "determinarão o futuro da civilização em que vivemos". Portanto, ainda que a possibilidade de êxito não seja garantida, realidade atual consiste em um caminho aberto, sendo que conforme afirma Castells (2020, s/p) o mundo já mudou, e nunca voltará a ser como aquele em que vivemos. O que não sabemos é como será. Talvez o melhor seria que o decidíssemos e o construíssemos, em vez de nos resignarmos ao destino.

Ao pensar no futuro, Santos (2020) aponta que há duas possibilidades. Uma pessimista que resulta de um regresso à "normalidade" de supremacia do homem como único ser racional supostamente capaz de dominar a natureza, portanto dando continuidade a destruição de todas as outras vidas de que é feito o planeta Terra e de políticas neoliberais continuando a minar a capacidade do Estado, considerando todas as demandas sociais inclusive a saúde. O prosseguimento desse encaminhamento poderá resultar mais e provavelmente mais graves pandemias, já que as populações estarão cada vez mais desamparadas e vulneráveis, posto a possibilidade/risco da continuidade das políticas neoliberais, regimes de extremadireita, práticas xenofóbicas, racistas etc. A outra possibilidade para o futuro, mais otimista, pressupõe uma articulação entre os processos políticos e os processos civilizatórios, com a emergência de modelos alternativos em que a humanidade assuma uma posição mais humilde, reveja as "necessidades desnecessárias" associadas ao consumismo. Nesse caso são necessárias soluções políticas, econômicas e sociais que garantam a continuidade da vida humana digna no planeta, sendo a mudança possível quando formos "capazes de imaginar o planeta como a nossa casa comum e a Natureza como a nossa mãe originária a quem devemos amor e respeito. Ela não nos pertence. Nós é que lhe pertencemos" (SANTOS, 2020, p.32).

Ressalta-se que essa perspectiva é compartilhada por vários cientistas, como geógrafos, filósofos, sociólogos e geofilósofos ${ }^{7}$ que prezam pela totalidade da bio e etnodiversidade do planeta, valorizam a força dos homens "lentos", que descobrem fabulações e lutam pela redução da desigualdade perversa entre os povos da Terra, numa práxis libertadora a partir do lugar. Nesse sentido, conforme amplamente recomendado por Milton Santos é preciso conhecer a constituição da realidade a partir da análise de

7 Enquanto "um método de leitura do mundo e da realidade" [...] "A geofilosofia busca (e oferece), diferentemente, uma visão mais orgânica e multidisciplinar, [...] a geofilosofia é uma opção pela harmonização das diversas possibilidades de compreensão da realidade e do mundo [...] reconhecendo que "o cerne de toda a experiência humana do (e no) mundo: o viver na Terra". (SANTOS e FERNANDES, 2015). 
como ocorre o uso do território, assim como valorizar os lugares de resistência estendendo-a para diferentes escalas, desde a local até a global.

\section{CONSIDERAÇÕES FINAIS}

Os apontamentos realizados a partir de lentes da Geografia, mesmo considerando um processo em curso, qual seja a pandemia da COVID-19, consiste na materialização de literaturizações do conhecimento que reascendem inquietações e nutrem reflexões que podem servir a um propósito útil em relação a escolhas de qual dos caminhos da encruzilhada a humanidade vai seguir após o período de quarentena.

A imposição da lógica da lentidão, enraizamento imobilidade em detrimento da lógica inerente à globalização caracterizada pela velocidade, fluidez e mobilidade, em certa medida serviu para mostrar que os movimentos impostos pela globalização, utilizando os termos de Santos (2000) consistem em "uma agitação cega", "um dinamismo do diabo", já que não são genuínos. Tanto a natureza, por exemplo, com a queda na quantidade de poluentes, como a maneira que lidamos com o nosso corpo, com o tempo e com o espaço, ao voltarmos para o lar e não sabermos como será o amanhã, nos permite a tomada de consciência da alienação que vivemos.

Nesse sentido, o período de isolamento consiste em uma oportunidade para cada um de nós, mas também para todos (posto que conforme nos ensino Morin et al (2007) cada um de nós é como um ponto de um holograma que, contém o todo planetário e também e parte dele) reformular novas ideias políticas de modo a resistir individual e coletivamente, às crises do período atual e pensar em possibilidades futuras.

Entretanto apesar de reconhecer que um novo mundo é possível, dadas as condições técnicas de nosso tempo, conforme nos ensinou Santos (2000), ao considerar a atual realidade sociopolítica, a mudança para um novo tempo civilizatório é complicada, pois ainda faltam condições basilares, para romper como os três modos de dominação que desde o século XVII cooptam pensamentos e gera "confusão dos espíritos", que impede o entendimento do mundo. O encaminhamento para a tomada de consciência do que é ser humanidade pressupõe romper com o colonialismo do saber, o que requer compromisso com os saberes fundados na ética e moralidade, além da recriação da Política genuína, da implementação de medidas estruturais, Morin el al (2007) aponta a possibilidade para uma antropolítica, ou seja uma política que opere na multidimensionalidade dos problemas humanos, pensando no devir planetário). Além de considerar a totalidade do mundo, a partir de uma perspectiva que considere a complementaridade, complexidade e, portanto a transdiciplinaridade do conhecimento. Por fim, concorda-se com Mantovani $(2020, \mathrm{~s} / \mathrm{p})$ no sentido que de que devemos "como lo reivindicara un famoso lema del mayo del 68, ser realistas y pedir lo imposible. Otro mundo diferente a este, ahora."

\section{REFERÊNCIAS}

BUSS, P. M.; PELLEGRINI FILHO, A. A saúde e seus determinantes sociais. Physis, Rio de Janeiro, v. 17, n. 1, p. 77-93, 2007. https://doi.org/10.1590/S0103-73312007000100006

CASTELLS, M. Pandemia, Público e Educação. Entrevista a Álex Rodríguez e Carina Farreras, La Vanguardia. Tradução: Antonio Martins. 14 abr 2020. Disponível em: <https://outraspalavras.net/poscapitalismo/castells-debate-a-pandemia-o-publico-e-a-educacao/> . Acesso em 24 abr. 2020.

CASTILHO. D. Um vírus com DNA da globalização: o espectro da perversidade. Opera Mundi, Plataforma digital da Uol. 26 março de 2020. Disponível em: https://operamundi.uol.com.br/coronavirus/63761/umvirus-com-dna-da-globalizacao-o-espectro-da-perversidade. Acesso em 20 abr. 2020. https://doi.org/10.4000/espacoeconomia.10332

CDSS - COMISSÃO PARA OS DETERMINANTES SOCIAIS DA SAÚDE. Redução das desigualdades no período de uma geração: igualdade na saúde através da ação sobre os seus determinantes sociais: relatório final. Genebra: OMS, 2010.

DAHLGREN, G., WHITEHEAD, M. Policies and Strategies to Promote Social Equity in Health. Stockholm: Institute for Futures Studies. 1991.

FERRÃO, J. A geografia da COVID-19: algumas precisões. Publico. Opinião Coronavírus. 16 de Abril de 2020. Disponível em: https://www.publico.pt/2020/04/16/sociedade/opiniao/geografia-covid19-precisoes1912527?fbclid=IwAR09iOOkE8aNISrt7I9HVYj90veYLSE3ysH3pQV58dDq8LRaOZfn-F0RPjl>. Acesso em 24 abr. 2020.

DOI:http://dx.doi.org/10.14393/Hygeia0054269 $\quad$ Hygeia $\quad$ Edição Especial: Covid-19, Jun./2020 $\quad$ p.25 - 35, $\quad$ pág. 34 
FIOCRUZ- Fundação Oswaldo Cruz, 2020. Página inicial: COVID-19- perguntas e respostas. Disponível em: <https://portal.fiocruz.br/coronavirus>. Acesso em: 20 de abr. de 2020.

FOUCAULT, M. Microfísica do poder. Rio de Janeiro: Edições Graal, 2010.

GRAMSCI, A. Selections from the prisions notebooks, New York: International Publishers, 1929.

HARVEY, D. Política anticapitalista em tempos de coronavírus. Jacobin Brasil, plataforma digital. 21 março 2020. Disponível em: <https://jacobin.com.br/2020/03/politica-anticapitalista-em-tempos-decoronavirus/?fbclid=IwAR2a_cgLFnF1zW7FI6TH9CDX_LOMMP7wUDeljxgckI6JiA-7Wxf5mNKQynE.>

Acesso em 25 abr. 2020.

KRENAK, A. O amanhã não está à venda. São Paulo: Companhia das Letras. 2020.

MANTOVANI, E. T. El Coronavirus más allá del Coronavirus: umbrales, biopolítica y emergências. Publicado em 19 de mar. de 2020. Disponível em<https://kaosenlared.net/el-coronavirus-mas-alla-delcoronavirus-umbrales-biopolitica-y-emergencias/>. Acesso em 24 de abr. de 2020.

MINAS GERAIS. Secretária de Estado de Saúde. Distribuição dos casos de COVID-19 em Minas Gerais. Disponível em: < https://www.saude.mg.gov.br/coronavirus >. Acesso em: 27 de abr. de 2020.

MORIN, E. Sentir mais do que nunca a comunidade de destino de toda a humanidade. Libération Samedi. 29 março 2020. Entrevista a Simon Blin. Traduzida por Luciano, Wagner Duarte Nabarro e Gustavo Teramatsu. Disponível em: <https://cjf.qc.ca/wp-content/uploads/2020/03/EdgardMorin_Mars2020.pdf> Acesso em: 23 de abr. de 2020.

A religação dos saberes: o desafio do século XXI. 3ed. Rio de Janeiro: Bertrand Brasil, 2002.

MORIN, E. et al. Educar na era planetária: o pensamento complexo como método de aprendizagem pelo erro e incerteza humana. São Paulo: Cortez; Brasília, DF: UNESCO, 2007.

NAVAS, M. E. Coronavírus: a temida 'doença X' antecipada pela OMS há dois anos e ignorada pelo mundo. O BBC News Mundo, 23 abr. 2020. Geral, Disponível em :<https://www.bbc.com/portuguese/geral-52383150>. Acesso em: 27 de abr. de 2020.

SANTOS, B. de S. A Cruel Pedagogia do Vírus. Biblioteca Nacional de Portugal. Edições Almedina, S.A. 2020.

SANTOS, M. Por uma outra globalização: do pensamento único à consciência universal. $3^{a}$. ed. Rio de Janeiro: Record, 2000.

A natureza do espaço: Técnica e tempo. Razão e emoção. 2.ed. São Paulo: Hucitec, 1997.

SANTOS R. J.; FERNANDES, P. I. B. Uma introdução à Geofilosofia. In: Paisagens da cana sem doce. .(org.). Ituiutaba: Barlavento, 2015.

SEADE. Sistema Estadual de Análise de Dados. São Paulo. Disponível em: <https://www.seade.gov.br/coronavirus/>>. Acesso em: 23 de abr. de 2020.

UFGRS. Universidade Federal do Rio Grande do Sul. Telessauders. Qual a diferença de distanciamento social, isolamento e quarentena? Disponível em: $<$ https://www.ufrgs.br/telessauders/posts_coronavirus/qual-a-diferenca-de-distanciamento-socialisolamento-e-quarentena/>. Acesso em: 26 de mai. de 2020.

VICENTE, E. Dispara o número de mortes por Covid-19 na periferia de São Paulo. Agora Folha Uol, plataforma digital. 16 mai. 2020. Disponível em: <https://agora.folha.uol.com.br/sao-paulo/2020/05/disparao-numero-de-mortes-por-covid-19-na-periferia-de-sao-paulo.shtml>. Acesso em: 26 de mai. de 2020.

ZANELLA, J. R. C. Zoonoses emergentes e reemergentes e sua importância para saúde e produção animal. Pesquisa agropecuária brasileira. Brasília, v.51 n.5, p. 510-519, 2016. https://doi.org/10.1590/S0100-204X2016000500011

ZIBECHI, R. Epidemia de neoliberalismo. La Jornada, Caderno Opinião. Plataforma digital. Publicado em 13 de março de 2020. Disponível em: <https://www.jornada.com.mx/2020/03/13/opinion/018a1pol. >. Acesso em: 23 de abr. de 2020.

WHO - World Health Organization. World Health Statistics 2018. 12 fevereiro de 2018. Disponível em: http://origin.who.int/emergencies/diseases/2018prioritization-report.pdf>. Acesso em: 23 de abr. de 2020. 